\title{
Effect of Behavioral Counseling with Shaping Techniques and Assertive Exercises on Student Self Affiliation
}

\author{
Pengaruh Konseling Behavioral dengan Teknik Shaping dan Latihan Asertif terhadap \\ Self Afiliasi Siswa
}

\author{
${ }^{\text {I Gede Krisna Yoga }}{ }^{1}$, I Ketut Gading ${ }^{2}$, I Ketut Dharsana ${ }^{3}$ \\ ${ }^{123}$ Universitas Pendidikan Ganesha \\ e-mail: putrimajiatulhibah58@gmai.com
}

Received July 28, 2017 Revised August 05, 2017 Accepted October 08, 2017 Published Online December 30, 2017

\section{Conflict of Interest}

\section{Disclosures:}

The authors declare that they have no significant competing financial, professional or personal interests that might have influenced the performance or presentation of the work described in this manuscript.

\begin{abstract}
The purpose of this study is to determine the effect of Behavioral Counseling With Shaping And Assertive Training Techniques To Self Affiliation and to know the difference of influence between behavioral counseling shaping techniques and assertive training techniques to self-affiliation of students of Class VIII SMP LAB UNDIKSHA.Desain design used is Pretes- Posttest Control GroupDesign. Data analysis method used is t-test. The result of this research is experiment group I shows thitung $>\mathrm{t}$ table $(5,503>1,997)$. Furthermore, treatment techniques of shaping and assertive training techniques show that $t$ count $>t$ table $(3.16>1.99)$. This proves that, there is a difference between shaping techniques with assertive training techniques against self-affiliation students. From the result of calculation average, obtained $127,57<119,69$, meaning that the mean value of shaping technique count is greater than assertive training technique. For that the third hypothesis that there are differences in the influence of behavioral counseling shaping techniques with assertive training techniques to self-affiliation class VIII students SMP LAB UNDIKSHA.
\end{abstract}

Keywords: behavioral counseling model, shaping technique, assertive training technique, self affiliation

\begin{abstract}
Abstrak: Tujuan penelitian ini adalah untuk mengetahui pengaruh konseling behavioral dengan teknik shaping dan latihan asertif terhadap self afiliasi dan untuk mengetahui adanya perbedaan pengaruh antara konseling behavioral teknik shaping dan teknik latihan asertif terhadap self afiliasi siswa Kelas VIII SMP LAB UNDIKSHA.Desain penelitian yang digunakan adalah Pretes-Posttest Control GroupDesain. Metode analisis data yang digunakan adalah t-test. Hasil penelitian ini yaitu kelompok eksperimen I menunjukkan thitung $>\mathrm{t}$ tabel $(5,503>1,997)$. Selanjutnya Treatmen teknik shaping dan teknik latihan asertif menunjukkan bahwa thitung $>$ t tabel $(3,16>1,99)$. Ini membuktikan bahwa, terdapat perbedaan antara teknik shaping dengan teknik latihan asertif terhadap self afiliasi siswa. Dari hasil rerata hitung, didapatkan $127,57<119,69$, artinya nilai rerata hitung teknik shaping lebih besar daripada teknik latihan asertif. Untuk itu hipotesis ketiga yaitu terdapat perbedaan pengaruh konseling behavioral teknik shaping dengan teknik latihan asertif terhadap self afiliasi siswa kelas VIII SMP LAB UNDIKSHA.
\end{abstract}

Kata Kunci: konseling behavioral, teknik shaping, teknik latihan asertif, self afiliasi

How to Cite: Yoga, I. G. K., Gading, I. K., \& Dharsana, I. K. (2017). Effect of Behavioral Counseling with Shaping Techniques and Assertive Exercises on Student Self Affiliation. Bisma, 1(2), 97-106. https://doi.org/10.23887/128202017 


\section{Pendahuluan}

Pengamatan peneliti di kelas VIII SMP LAB UNDIKSHA Tahun Pelajaran 2016-2017, peneliti melihat ada beberapa siswa yang memiliki gejala dan prilaku seperti kurangnya kerja sama atan siswa, tidak pernah aktif dengan kelompok belajar, dan tidak bisa bersekutu dengan anggota kelompok. Namun tidak semua siswa memiliki kepribadian yang sama, ada juga siswa yang memiliki kerja sama atan siswa, aktif dengan kelompok belajar, dan bisa bersekutu dengan anggota kelompok.

Dharsana,(2014:1001) Self Afiliation adalah "kebutuhan untuk bersekutu dengan orang lain, setia dan patuh kepada teman, berpartisipasi aktif dalam kelompok dan kekeluargaan, melakukan sesuatu bagi teman-teman, membentuk persahabatan baru. Menurut David Mcclelland beraffiliasi merupakan kebutuhan berkuasa dan kebutuhan berprestasi untuk memperoleh petunjuk tentang potensi seseorang sebagai pengusaha. Bila pada seseorang kebutuhan berafiliasi dan kebutuhan untuk berkuasa lebih kuat dari pada kebutuhan berprestasi, tipis kemungkinan orang bersangkutan untuk sukses sebagai pengusaha (dalam Ensiklopedi Nasional Indonesia, 1988:107).)(Yoshida, Hayakawa, \& Hatsuk(A. Bendaoud, M.C. Chabou, O. Kolli, O. Bouzidi \& ï, 2015; Aarseth, 2009; DANIEL KALLÓS, 2009; Filiz Boyaci \& Topçu, 2014; Guðmundsson \& Crocker, 2010; Jódar, Ortiz, Martí, \& Alós, 2004; Orhan, Y1lmaz, \& I, 1994; SkelaSavič \& Lorber, 2014; Soto Carmona David Ruiz U A D, 1970; 吴开业, 2008; 徐et al., 2001)

Pemberian layanan bimbingan konseling yang digunanakan untuk mengembangkan self afiliasisiswa dapat dilakukan dengan beberapa upaya seperti inovasi dalam proses pembelajaran, upaya pelatihan melalui kegiatan ekstrakurikuler, serta dengan treatmen psikologi atau layanan bimbingan konseling. Sehubungan dengan hal tersebut, maka peneliti memilih untuk mengembangkan self afiliasisiswa melalui pendekatan bimbingan konseling. Dharsana (2015:10) menjelaskan prosedur pelaksanaan model konseling Behavioral sebagai berikut:1).Mengobservasi gejala self afiliasi,2).Mentabulasi gejala self afiliasi,3).Menganalisisgejalaself afiliasi4).Mengidentifikasi gejalaself afiliasi,5).Melakukandiagnosa,6). Melakukanprognosa,7).Melakukan tindakan/treatmentmenurut corey (dalam Dharsana 2014:587) dalam penerapan teori behavioral atau tingkah laku antara lain: 1) Desensitisasi Sistematik,2)Teknik-teknik pembanjiran, 3) Latihan Asertif, 4) terapi aversi, 5) pengondisian operan, 6) penguatan positif, 7) pembalikan, 8) pembentukan respon (shaping), 9) perkuatan intermiten, 10) penghapusan, 11) percontohan (modeling), 12) token economy. 13) relaksasi. Berdasarkan hal tersebut, maka dalam penelitian ini peneliti memilih dua teknik yaitu teknik shaping dan teknik latihan asertif.

Menurut (Hardianti, Am, \& Huda, 2010; Leal, Arnaldo, \& Montevechi, 2008; Park, Chang, Park, \& Lee, 2006; Rahim \& Kandlawala, 2004)), Shaping adalah membentuk tingkah laku baru yang sebelumnya belum ditampilkan dengan memberikan reinforcement secara sistematik dan langsung setiap kali tingkah laku ditampilkan. Tingkah laku diubah secara bertahap dengan memperkuat unsure-unsur kecil tingkah laku baru yang diinginkan secara berturut-turut sampai mendekati tingkah laku akhir. Konselor membentuk tingkah laku yang lebih adaptif dengan member reinforcement primer maupun sekunder.Dharsana (2015), penelitian dari teknik shaping memiliki prosedur yaitu: 1) Menyebarkan lembar kuesioner self afiliasi, 2). Menganalisis hasil kuesioner self afiliasi, 3). Menulis dan menyajikan RPBK yang terkait self afiliasi, 4). Melakukan treatment dengan menggunakan teknik shaping. Dengan langkahlangkah 1) Melakukan komunikasi langsung/wawancara, 2). Menetapkan target perilaku spesifik yang akan dicapai bersama konseli.3). Membuat perencanaan dengan membuat tahapan pencapaian perilaku mulai dari perilaku awal sampai perilaku akhir 4). Penetapan waktu pemberian reinforcement pada setiap tahap program.

Corey (1995: 87) menyatakan bahwa "asumsi dasar dari latihan asertif adalah bahwa setiap orang mempunyai hak untuk mengungkapkan perasaannya, pendapat, apa yang diyakini serta sikapnya terhadap orang lain dengan tetap menghormati dan menghargai hak-hak orang tersebut". Teknik ini digunakan untuk melatih klien yang mengalami kesulitan untuk menyatakan diri bahwa tindakannya adalah layak atau benar.Latihan ini terutama berguna di antaranya untuk membantu individu yang tidak mampu mengungkapkan perasaan tersinggung, kesulitan menyatakan "tidak", mengungkapkan afeksi dan respon posistif lainnya. Penelitian teknik relaksasi memiliki prosedur yaitu: 1) menyebarkan lembaran kuesioner Self afiliasi, 2) menganalisis hasil kuesioner Selfafiliasi, 3) menulis dan menyajikan RPBK yang terkait dengan teknik latihan asertif, 4) melakukan treatmen dengan menggunakan teknik latihan asertif.

Dalam penelitian ini dirumuskan beberapa permasalahan yaitu: 1)Terdapat beberapa siswa yang mengalami self afiliasi yang rendah. 2) Pemahaman siswa terhadap pentingnya self afiliasibelum optimal. 
3) Pelaksanaan bimbingan dalam bentuk konseling dengan berbagai teknik belum dilaksanakan secara efektif salah satunya yaitu pengaruh model konseling behavioral teknik shaping dan teknik latihan asertif untuk mengembangkan self afiliasi siswa kelas VIII SMP LAB UNDIKSHA.

Tujuan penelitian ini adalah: 1) Untuk mengetahui teknik shaping model konseling behavioral berpengaruhdalam mengembangkanself afiliasipada siswa kelas VIII 3 SMP LAB UNDIKSHA. 2) Untuk mengetahui teknik latihan asertif model konseling behavioralberpengaruh dalammengembangkanself afiliasipada siswa kelas VIII 4 SMP LAB UNDIKSHA. 3) Untuk mengetahui perbedaan pengaruhteknik shaping dengan teknik latihan asertif model konseling behavioral dalam mengembangkan self afiliasisiswa.

\section{Metode}

Desain Eksperimen merupakan semua proses yang diperlukan dalam perencanaan dan pelaksanaan penelitian (Umar,2004:30). Dalam penelitian ini, desain penelitian yang digunakan adalah "Pretes-Posttest Control Group Group Desain. Menurut Sukardi (2012:186), "Pretes-Posttest Control Group Group Desain" merupakan model eksperimen semu ("quasi ekperiment"). Dantes (2012:97) menyatakan bahwa, dalam penelitian kuasi sering digunakan "intact group", seperti kelas sehingga randomisasi tidak dapat dilakukan.

Teknik pengumpulan data dalam penelitian yaitu 1) Teknik Pengamatan (observasi), 2) Teknik Wawancara, 3) Kuesioner, 4) Dokumen dan Artefak. Populasi dalam penelitian ini adalah siswa kelas VIII 3, VIII 4, VIII 5 di SMP LAB UNDIKSHA dengan jumlah 3 kelas. Yang jumlah totalnya 100 orang.

Langkah-langkah penelitian ini meliputi: 1) Persiapan eksperimen (menyusun istrumen, mengurus Izin penelitian, melakukan observasi awal, menguji instrumen kuesioner self afiliasiuji Coba Instrumen, dan menyusun jadwal pelaksanaan eksperimen). 2) Tahap Pelaksanaan Eksperimen (pelaksanaan pre test, pelaksanaan layanan meliputi bimbingan klasikal, bimbingan kelompok, konseling kelompok, konseling individu). 3) Tahap Akhir (pemberian post-test, analisis data).

Teknik pengumpulan data dalam penelitian yaitu 1) Teknik Pengamatan (observasi), 2) Teknik Wawancara, 3) Kuesioner, 4) Dokumen dan Artefak.

Data-data yang terkumpul melalui lembar observasi, lembar wawancara, dan buku harian akan dianalisis menggunakan teknik Deskriptif Kualitatif. Kemudian data-data yang terkumpul melalui kuesioner self afiliasi, dianalisis menggunakan teknik Deskriptif Kuantitatif menggunakan rumus t-test.

\section{Hasil dan Pembahasan}

Variabel yang dikaji dalam penelitian ini adalah self afiliasi siswa di kelas VIII 3, VIII 4 dan VIII 5 SMPLAB UNDIKSHA. Data hasil observasi terhadap kelompok eksperimen I dalam setiap layanan model konseling behavioral teknik shapingterkait gejala-gejala self afiliasinegatif (-) yaitu dalam bimbingan klasikal terdapat 8 orang siswa, dalam bimbingan kelompok terdapat 8 orang siswa, dalam konseling kelompok 1 orang siswa.

Data hasil observasi terhadap kelompok eksperimen II dalam setiap pelaksanaan layanan model konseling behavioral dengan teknik latihan asertif terkait gejala-gejala self afiliasinegatif (-)yaitu dalam bimbingan klasikal, terdapat 8 orang siswa, dalam bimbingan kelompok terdapat 8 orang siswa, dalam konseling kelompok terdapat 1 orang siswa.

Melakukan rekapitulasi perhitungan ukuran tendasi sentral dan ukuran penyebaran data self afiliasi yaitu, selanjutnya dilakukan uji normalitas data sebagai berikut: 


\begin{tabular}{|l|l|l|l|l|l|l|l|}
\hline \multicolumn{2}{|l|}{ Kode } & \multicolumn{2}{l|}{$\begin{array}{l}\text { Kolmogrov - } \\
\text { Smirnov }\end{array}$} & \multicolumn{3}{l|}{ Shapiro - Wilk } \\
\cline { 2 - 9 } \multicolumn{2}{|c|}{} & Tatistic & f & ig & Tatistic & f & ig \\
\hline \multirow{4}{*}{ Nilai } & $\begin{array}{l}\text { Teknik } \\
\text { Shaping }\end{array}$ & 145 & 3 & 075 & 924 & 3 & 024 \\
\cline { 2 - 8 } & $\begin{array}{l}\text { Teknik } \\
\text { Asertif }\end{array}$ & 109 & 3 & $200^{*}$ & 969 & 3 & 447 \\
\cline { 2 - 8 } & Kontrol & 102 & 4 & $200^{*}$ & 974 & 4 & 588 \\
\hline & & & & & & & \\
\hline
\end{tabular}

Dilihat dari hasil output SPSS tests normality menunjukan nilai signifikansi Kolmogorov-Smirnov (KS) masing- masing kelompok yaitu, Teknik Shaping : $(0,075>0,05)$, teknik latihan asertif $(0,200>0,05)$ dan kelompk kontrol $(0,200>0,05)$. Karena signifikan hasil lebih besar dari signifikan uji (K-S > $\mathbf{\alpha})$, maka dapat disimpulkan bahwa variabel Self Afiliasi teknik shaping, teknik latihan asertif dan kelompok kontrolberdistribusi secara normal.

Data buku harian siswa kelompok eksperimen I terkait afiliasidisajikan dalam tabel 4.5 dibawah ini:

Tabel 4.5 Skor Buku Harian siswa Kelompok Eksperiment I

\begin{tabular}{|c|c|c|c|c|c|c|c|}
\hline \multicolumn{7}{|c|}{ HARI } & \multirow[t]{2}{*}{ SKOR } \\
\hline 1 & 2 & 3 & 4 & 5 & 6 & 7 & \\
\hline 2 & 5 & 7 & 8 & 10 & 11 & 15 & 58 \\
\hline
\end{tabular}

Selanjutnya skor buku harian siswa kelompok eksperimen I dimasukkan ke dalam grafik harian sebagai berikut:

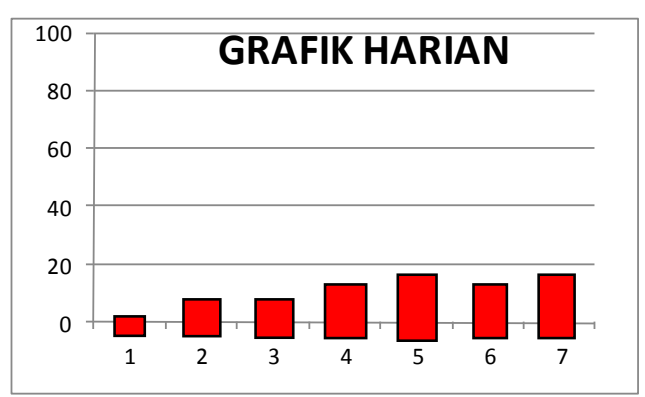

Setelah diketahui harian buku harian siswa, selanjutnya data tersebut dimasukkan ke dalam data buku harian mingguan sebagai berikut:

\begin{tabular}{|c|c|c|c|c|c|c|c|c|c|}
\hline \multirow[t]{2}{*}{ MINGGU } & \multicolumn{7}{|c|}{ HARI } & \multirow[t]{2}{*}{ SKOR } & \multirow[t]{2}{*}{ Rata-Rata } \\
\hline & 1 & 2 & 3 & 4 & 5 & 6 & 7 & & \\
\hline I & 2 & 5 & 7 & 8 & 10 & 11 & 15 & 58 & 8,2 \\
\hline II & 15 & 20 & 25 & 30 & 35 & 40 & 45 & 210 & 30 \\
\hline III & 45 & 50 & 55 & 60 & 65 & 60 & 55 & 390 & 55,7 \\
\hline IV & 60 & 70 & 75 & 80 & 85 & 87 & 88 & 545 & 77,8 \\
\hline
\end{tabular}


Selanjutnya skor buku harian mingguan siswa kelompok eksperimen I dimasukkan ke dalam grafik mingguan sebagai berikut:

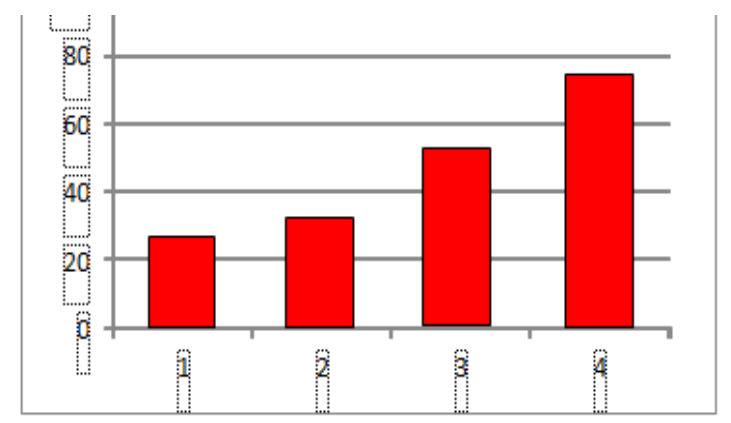

Data hasil kuesioner self afiliasi kelompok eksperimen I dalam Pre-Test diketahui bahwa 10 orang siswa berada dalam kategori tinggi,5 orang siswa berada dalam kategori sedang,dan 8 orang siswa berada dalam kategori rendah, 10 orang kategori sangat tinggi. Kemudian dalam "Post-Test" diketahui bahwa 31 orang siswa berada dalam kategori sangat tinggi, 2 orang siswa berada dalam kategori tinggi.Hasil analisis data kuesioner, diketahui harga t hitung lebih besar daripada harga $t$ table $(5,503>1,997)$ taraf siginifikansi 5\%) sehingga $\mathrm{H} 0$ ditolak dan $\mathrm{H} 2$ diterima. Ini berarti, terdapat perbedaan yang signifikan self afiliasisiswa kelas VIII 3antara sebelum dan sesudah diberikan treatmentteknik shaping model konseling behavioral. Dari nilai rerata hitung, diketahui bahwa rerata self afiliasisiswa setelah diberikan treatment teknik shapingmodel konseling behavioral lebih besar daripada sebelum diberikan treatment.

Data hasil kuesioner self afiliasi kelompok eksperimen II dalam Pre-Test diketahui bahwa 5 orang siswa berada dalam kategori sangat tinggi, 10 orang berada dalam kategori tinggi, dan 10 orang siswa berada dalam kategori sedang dan 8 orang berada dalam kategori rendah.Kemudian dalam Post-Testdiketahui bahwa 30 orang siswa berada dalam kategori sangat tinggi, dan 3 orang siswa berada dalam kategori tinggi. Hasil analisis kuesioner, diketahui harga t hitung lebih besar daripada harga $t$ table $(2,114>1,997)$ taraf siginifikansi 5\%) sehingga $\mathrm{H} 0$ ditolak dan Ha diterima. Ini berarti, terdapat perbedaan yang signifikan self afiliasisiswa kelas VIII 4antara sebelum dan sesudah diberikan treatmentteknik latihan asertifmodel konseling behavioral. Dari nilai rerata hitung diketahui bahwa rerata self afiliasisiswa setelah diberikan treatment teknik latihan asertifmodel konseling behavioral lebih besar daripada sebelum diberikan treatment.

Hasil analisis data kuesioner selfafiliasi kelompok eksperimen I dan eksperimen II, diketahui bahwa harga $\mathrm{F}$ hitung $<\mathrm{F}$ table $(1,106<4,00)$ taraf signifikansi $5 \%)$, ini berarti $\mathrm{H} 3$ diterima dan H0 ditolak; jadi varians homogen. Selanjutnya, dilanjutkan dengan analisis menggunakan $\mathrm{t}$-test dengan hasil $\mathrm{t}$ hitung $>\mathrm{t}$ table $(5,503>1,997138)$, sehingga $\mathrm{H} 3$ diterima dan $\mathrm{H} 0$ ditolak.

\section{Teknik Shaping dalam Model Konseling Behavioral Berpengaruh terhadap Self Afiliasi Siswa Kelas VIII 3}

Siswa kelas VIII 3 SMP LAB UNDIKSHA, berdasarkan hasil pengamatan telah menunjukkan gejalagejala seperti sulit bersekutu dengan orang lain, tidak setia dan patuh kepada teman, tidak berpartisifasi aktif dalam kelompok, tidak melaklukan sesuatu bagi teman, sulit membentuk persahabatan baru. Gejalagejala tersebut diatas, merupakan gejala self afiliasi yang rendah. Sehingga, gejala-gejala tersebut penting untuk diperhatikan agar siswa memiliki pribadi afiliasi yang stabil.

Untuk melakukan treatment terhadap self afiliasi siswa yang rendah tersebut, dalam layanan bimbingan konseling terdapat berbagai macam teori konseling yang dapat diaplikasikan salah satunya yaitu teori konseling behavioral. Model konseling behavioral adalah proses pembentukan respon-respon tingkah laku dengan prosedur dan langkah yang telah ditentukan model konseling behavioral ini bersifat konfrontatif dan aktif, membawa aspek-aspek masa lalu yang relevan ke saat sekarang, pengaplikasian model konseling behavioral ini memerlukan teknik. Dalam hal ini, untuk memberikan treatment terhadap self afiliasi siswa, teknik yang digunakan adalah teknik shaping.

Teknik shaping adalahteknik pembentukan dan pengembangan tingkah laku baru yang sebelumnya belum ditampilkan dengan memberikan reinforcement secara sistematik dan langsung setiap kali tingkah laku ditampilkan. Dalam hal ini, teknik shaping diaplikasikan dalam model konseling behavioral berupa 
layanan bimbingan klasikal, bimbingan kelompok, konseling kelompok, dan konseling individu pada siswa kelas VIII 3 SMP LAB UNDIKSHA sebagai kelompok eksperimen I.

Hasil observasi yang dilakukan dalam setiap pelaksanaan layanan, menunjukkan bahwa terjadi penurunan jumlah siswa yang mengalami self afiliasi yang rendah. Hasil observasi dalam bimbingan klasikal menemukan 8 orang siswa yang menunjukkan gejala self afiliasi negatif yang selanjutnya direkomendasikan mengikuti bimbingan kelompok. Kemudian hasil observasi dalam bimbingan kelompok 8 orang siswa yang menunjukkan gejala self afiliasi negatif yang selanjutnya direkomendasikan mengikuti konseling kelompok. Selanjutnya hasil observasi dalam konseling kelompok menemukan 1 orang siswa menunjukkan gejala self afiliasi negatif yang selanjutnya direkomendasikan mengikuti konseling individu. Setelah dilakukan konseling individual, siswa sudah mampu menunjukkan gejala-gejala self afiliasi yang bersifat positif. Dari data hasil observasi tersebut, dapat diketahui bahwa setelah diberikan treatment model konseling behavioral teknik shaping terjadi penurunan self afiliasi siswa yang bersifat negatif. Sehingga, jumlah siswa yang mengalami gejala-gejala self afiliasi yang rendah dapat berkurang.

Temuan empiris pada penelitian ini menyatakan bahwa teknik shaping dalam model konseling behavioral berpengaruh terhadap self afiliasi siswa kelas VIII 3. Hasil uji F diketahui bahwa kedua varians homeogen dimana Fhitung $<$ Ftabel $(1,106<4,00)$. Kemudian dilakukan uji $t$ didapatkan hasil bahwa Harga $t$ hitung diperoleh 5,503dan Harga $t$ tabel sebesar 1,997138.. Jika dibandingkan Harga $t$ hitung dengan Harga $t$ tabel didapatkan bahwa $(5,503>1,997138)$ artinya Harga $t$ hitung $>$ Harga $t$ tabel dengan $d b$ 33 dan 32 dan taraf siginifikansi 5\% $(\alpha=0,05)$. Ini berarti bahwa Ho ditolak dan Ha diterima. Untuk itu, hipotesis pertama yaitu terdapat pengaruh Konseling Behavioral teknik Shaping terhadap "Self Afiliasi" siswa kelas VIII 3 SMP LAB UNDIKSHA diterima. Sehingga dapat diketahui bahwa teknik shaping dalam model konseling behavioral berpengaruh terhadap self afiliasi siswa kelas VIII 3 SMP LAB UNDIKSHA.

\section{Teknik Latihan Asertif dalam Model Konseling Behavioral Efektif terhadap Self AfiliasiSiswa Kelas VIII 4}

Siswa kelas VIII 4 SMP LAB UNDIKSHA, berdasarkan hasil pengamatan telah menunjukkan gejalagejala seperti sulit bersekutu dengan orang lain, tidak setia dan patuh kepada teman, tidak berpartisifasi aktif dalam kelompok, tidak melaklukan sesuatu bagi teman, sulit membentuk persahabatan baru. Gejalagejala tersebut diatas, merupakan gejala self afiliasi yang rendah. Sehingga, gejala-gejala tersebut penting untuk diperhatikan agar siswa memiliki self afiliasi yang stabil.

Untuk melakukan treatment terhadap self afiliasi siswa yang rendah tersebut, dalam layanan bimbingan konseling terdapat berbagai macam teori konseling yang dapat diaplikasikan salah satunya yaitu teori konseling behavioral. Model konseling behavioral adalah proses pembentukan respon-respon tingkah laku dengan prosedur dan langkah yang telah ditentukan. Secara praktis, pengaplikasian model konseling behavioral ini memerlukan teknik. Dalam hal ini, untuk memberikan treatment terhadap self afiliasi siswa kelas VIII 4, teknik yang digunakan adalah teknik latihan asertif.

Teknik Latihan Asertif adalah usaha untuk membantu individu yang tidak mampu mengungkapkan perasaan tersinggung, kesulitan menyatakan "tidak", mengungkapkan afeksi dan respon posistif lainnya. Dalam hal ini, teknik latihan asertif diaplikasikan dalam model konseling behavioral berupa layanan bimbingan klasikal, bimbingan kelompok, konseling kelompok, dan konseling individu pada siswa kelas VIII 4 SMP LAB UNDIKSHA sebagai kelompok eksperimen II.

Hasil observasi yang dilakukan dalam setiap pertemuan, menunjukkan bahwa terjadi penurunan jumlah siswa yang mengalami self afiliasi yang rendah. Hasil observasi dalam bimbingan klasikal menemukan 8 orang siswa menunjukkan gejala self afiliasi negatif yang selanjutnya direkomendasikan mengikuti bimbingan kelompok. Kemudian hasil observasi dalam bimbingan kelompok 8 orang siswa yang menunjukkan gejala self afiliasi negatif yang selanjutnya mengikuti konseling kelompok. Kemudian hasil observasi dalam konseling kelompok menemukan 1 orang siswa menunjukkan gejala self afiliasi yang bersifat negatif yang selanjutnya direkomendasikan mengikuti konseling individu. Setelah konseling individu dilaksanakan, siswa sudah mampu menunjukkan gejala self afiliasi yang bersifat positif. Dari data hasil observasi tersebut, dapat diketahui bahwa setelah diberikan treatment model konseling behavioral teknik latihan asertif, terjadi penurunan self afiliasi siswa yang bersifat negatif. Sehingga, jumlah siswa yang mengalami gejala-gejala self afiliasi yang rendah dapat berkurang.

Temuan empiris pada penelitian ini menyatakan bahwa teknik latihan asertif dalam model konseling behavioral berpengaruh terhadap self afiliasi siswa kelas VIII 4. Hasil uji F diketahui bahwa kedua varians 
homeogen dimana $\mathrm{F}$ hitung $<\mathrm{F}$ tabel $(1,106<4,00)$. Kemudian dilakukan uji t didapatkan hasil bahwa Harga $t$ hitung diperoleh 2,114 dan Harga t tabel sebesar 1,997138. Jika dibandingkan Harga $t$ hitung dengan Harga t tabel didapatkan bahwa $(2,114>1,997138)$ artinya Harga $t$ hitung $>$ Harga $t$ tabel dengan $d b$ 31 dan 31 dan taraf siginifikansi 5\% $(\alpha=0,05)$. Ini berarti bahwa Ho ditolak dan Ha diterima. Untuk itu, hipotesis ke dua yaitu terdapat pengaruh Konseling Behavioral teknik Latihan Asertif terhadap "Self Afiliasi" siswa kelas VIII 4 SMP LAB UNDIKSHA diterima. Sehingga dapat diketahui bahwa teknik latihan asertif model konseling behavioral berpengaruh terhadap self afiliasi siswa kelas VIII 4 SMP LAB UNDIKSHA.

\section{Perbedaan PengaruhTeknik Shaping dengan Teknik Latihan Asertif Model Konseling Behavioral terhadap Self AfiliasiSiswa}

Model konseling behavioral adalah proses pembentukan respon-respon tingkah laku dengan prosedur dan langkah yang telah ditentukan. Secara praktis, pengaplikasian model konseling behavioral ini memerlukan teknik. Dalam hal ini, untuk memberikan treatment terhadap self afiliasi siswa, teknik yang digunakan adalah teknik shaping dan latihan asert.

Teknik shaping adalah teknik pembentukan dan pengembangan tingkah laku baru yang sebelumnya belum ditampilkan dengan memberikan reinforcement secara sistematik dan langsung setiap kali tingkah laku ditampilkan

Dalam hal ini, teknik shaping diaplikasikan dalam model konseling behavioral berupa layanan bimbingan klasikal, bimbingan kelompok, konseling kelompok, dan konseling individu pada siswa kelas VIII 3 SMP LAB UNDIKSHA sebagai kelompok eksperimen I.

Teknik latihan asertifadalah usaha untuk membantu individu yang tidak mampu mengungkapkan perasaan tersinggung, kesulitan menyatakan "tidak", mengungkapkan afeksi dan respon posistif lainnya

Dalam hal ini, teknik latihan asertif diaplikasikan dalam model konseling behavioral berupa layanan bimbingan klasikal, bimbingan kelompok, konseling kelompok, dan konseling individu pada siswa kelas VIII 4 SMP LAB UNDIKSHA sebagai kelompok eksperimen II.

Teknik shaping dengan teknik latihan asertif telah terbukti efektif dalam mengembangkan self afiliasi siswa pada kelompok eksperimen. Dari hasil observasi dan pengujian data kuesioner self afiliasi pada pretest dan post-test, terdapat perbedaan yang signifikan. Sehingga, gejala-gejala self afiliasi siswa yang bersifat negatif mengalami penurunan.

Temuan empiris pada penelitian ini, menyatakan bahwa terdapat perbedaan pengaruh antara teknik shaping dengan teknik latihan asertif model konseling behavioral terhadap self afiliasi siswa. Hasil uji $\mathrm{F}$ menyatakan bahwa kedua varian homogen dimana Fhitung < Ftabel yaitu $(1,106<4,00)$. Dari hasil uji $t$ bahwa Harga $t$ hitung diperoleh 3,16dan Harga $t$ tabel sebesar 1,99. Jika dibandingkan Harga $t$ hitung dengan Harga $t$ tabeldidapatkan bahwa $(3,16>1,99)$.artinya Harga $t$ hitung $>$ Harga $t$ tabel. Ini membuktikan bahwa, terdapat perbedaan antara teknik shaping dengan teknik latihan asertif model konseling behavioral terhadap self afiliasi siswa. Dari hasil rerata hitung, didapatkan $\overline{X_{1}}=127,57>\overline{X_{2}}$ $=119,69$, artinya nilai rerata hitung teknik shaping lebih besar darari pada teknik latihan asertif. Ini berarti Ha diterima dan Ho ditolak. Untuk itu hipotesis ketiga yaitu terdapat perbedaan pengaruh antara Konseling Behavioral teknik Shaping dan teknik Latihan Asertif terhadap "Self Afiliasi" siswa kelas VIII SMP LAB UNDIKSHA diterima. Sehingga dapat diketahui bahwa terdapat perbedaan pengaruh teknik shaping dengan teknik latihan asertif model konseling behavioral terhadap self afiliasi siswa kelas VIII SMP LAB UNDIKSHA dimana teknik shaping lebih efektif terhadap self afiliasi siswa.

\section{Kesimpulan}

Dari penelitian yang telah dilakukan, dapat disimpulkan sebagai berikut:

1. Siswa kelas VIII 3 SMP LAB UNDIKSHA, menunjukkan gejala-gejala self afiliasi yang rendah. Gejala-gejala tersebut penting untuk diperhatikan agar pribadi afiliasi siswa stabil. Untuk itu, treatment Model Konseling Behavioral teknik shaping, merupakan alternatif solusi terhadap permasalahan tersebut. Setelah treatment ini diberikan, hasil observasi menunjukkan bahwa terjadi penurunan jumlah siswa yang mengalami self afiliasi yang rendah. Temuan empiris juga menemukan bahwa terdapat perbedaan antara skor sebelum dan sesudah diberikan treatment dimana Harga thitung 
$>$ ttabel $(5,503>1,997)$. Sehingga, teknik shaping model konseling behavioral ini berpengaruh dalam mengembangkan self afiliasi siswa kelas VIII 3 SMP LAB UNDIKSHA.

2. Siswa kelas VIII 4 SMP LAB UNDIKSHA, menunjukkan gejala-gejala self afiliasi yang rendah. Gejala-gejala tersebut penting untuk diperhatikan agar siswa memiliki pribadi afiliasi yang stabil. Untuk itu, treatment model konseling behavioral teknik latihan asertif merupakan alternatif solusi terhadap permasalahn tersebut. Setelah treatment diberikan, hasil observasi yang menunjukkan terjadi penurunan jumlah siswa yang mengalami self afiliasi yang rendah. Temuan empiris menyatakan bahwa terdapat perbedaan antara skor sebelum dan sesudah diberikan treatment dimana Harga thitung $>$ ttabel $(2,114>1,997)$. Sehingga, teknik latihan asertif dalam model konseling behavioral berpengaruh terhadap self afiliasi siswa kelas VIII 4 SMP LAB UNDIKSHA.

3. Model Konseling Behavioral teknik shaping dan teknik latihan asertif telah terbukti berpengaruh dalam mengembangkan self afiliasi siswa. Temuan empiris menyatakan bahwa terdapat perbedaan antara teknik shaping dengan teknik latihan asertif model konseling behavioral pada saat digunakan untuk men treatment self afiliasi siswa. Hasil uji $\mathrm{F}$ menyatakan bahwa kedua varian homogen. Kemudian hasil uji t menyatakan bahwa Harga t hitung $>$ Harga $t$ tabel yaitu $(3,16>1,99)$. Hasil rerata hitung, juga didapatkan $=127,57>=119,69$. Sehingga, terdapat perbedaan pengaruh teknik shaping dengan teknik latihan asertif dalam model konseling behavioral dalam mengembangkan self afiliasi siswa kelas VIII SMP LAB UNDIKSHA.

\section{Referensi}

Anwar, Zainul. (2014). Praktik Konseling. Malang: Universitas Muhamadiyah Malang Press

Badri Sutrisno. (2012).Metode Statistik untuk Penelitian Kuantitatif. Yogyakarta: Ombak (Anggota IKAPI)

Bungin, Burhan. (2011). Metodelogi Penelitian Kuantitatif, komunikasi, ekonomi dan kebijakan public serta ilmuilmu sosial lainnya. Jakarta: Kencana Perdana Media Group

Corey, Gerald. (2013). Teori dan Praktek Konseling \& Psikoterapi. Bandung: PT. Refika Aditama

Dantes, Nyoman. (2012). Metode Penelitian. Yogyakarta: CV Andi Offset

Dharsana, Ketut. (2013). Modul Teori-Teori Konseling. Singaraja: Jurusan Bimbingan Konseling, FIP UNDIKSHA

------. (2013b). Pengembangan Pribadi Konselor. Singaraja: Jurusan Bimbingan Konseling, FIP UNDIKSHA

(2014). Model-Model Teori, Teknik, Skill Bimbingan Konseling untuk Penulisan RPBK, Proposal, Skripsi, Tesis. Singaraja: BK FIP UNDIKSHA

------. (2015). RPBK Seri Bimbingan Klasikal, Bimbingan Kelompok, Konseling Kelompok, Konseling Individual untuk Pengembangan Self Achievment. Singaraja: BK FIP UNDIKSHA

Firdaus, M. Aziz. (2012). Metode Penelitian. Tanggerang Selatan: Jelajah Nusa

Gudnanto. (2012). Pendekatan Konseling. Jawa Tengah: Fakultas Keguruan Ilmu Pendidikan, Universitas Muria Kudus

Gunawan, Muhammad Ali.(2013). Statistik untuk Penelitian Pendidikan. Yogyakarta: Parama Publising

Janet S. McCord and Edwin S. Shneidman. (2015). Psychache. Diakses melalui: http://www.suicidefindinghope.com/content/psychache Pada tanggal: 23 Desember 2015

Juliansyah, Noor. (2011). Metodologi Penelitian. Jakarta: Kencana Perdana Media Group

Komalasari, G., Wahyuni, E.,dkk. (2011). Teori dan Teknik Konseling. Jakarta: PT Indeks. 
Koyan, Wayan. (2012). Statistik Pendidikan, teknik analisis data kuantitatif. Singaraja: Universitas Pendidikan Ganesha Press

Lesmana, Jeanette Murad. (2013). Dasar-Dasar Konseling. Jakarta: Universitas Indonesia Press

Lumongga Lubis, Namora. (2011). Memahami Dasar-Dasar Konseling dalam Teori dan Praktik. Jakarta: Kencana Prenada Media Group

Narbuko, Cholid., dan Achmadi, Abu. (2013). Metodologi Penelitian. Jakarta: PT Bumi Aksara

Nasution. (2008). Metode Research (penelitian ilmiah). Jakarta: PT Bumi Aksara

Reksoatmodjo, Tedjo N. (2009). Statistika untuk Psikologi dan Pendidikan. Bandung: PT Refika Aditama

Sudrajat, Ahmad. (2008). Pendekatan Konseling Behavioral. Diakses melalui :https:/akhmadsudrajat.wordpress.com/2008/01/23/pendekatan-konseling-behavioral/ Pada tanggal : 1 Desember 2015

Setyosari, Punaji. (2012). Metode Penelitian Pendidikan dan Pengembangan. Jakarta: Kencana Prenada Media Group

Sudaryono, dkk. (2013). Pengembangan Instrumen Penelitian Pendidikan. Yogyakarta: Graha Ilmu

Suharsaputra, Unhar. (2012). Metode Penelitian kuantitatif, kualitatif dan tindakan. Bandung: PT Refika Aditama

Sukardi. (2012). Metodelogi Penelitian Pendidikan Kompetensi dan Praktiknya. Jakarta: PT Bumi Aksara

Sukitman, Tri. (2015). Bimbingan Konseling Berbasis Pendidikan Karakter. Yogyakarta: Diva Press

Surya, Mohammad. (2003). Teori-Teori Konseling. Bandung: Pustaka Bani Quraisy

Umar, Husein. (2004). Metode Penelitian untuk Skripsi dan Tesis Bisnis. Jakarta: PT Raja Grafindo Persada

A. Bendaoud, M.C. Chabou, O. Kolli, O. Bouzidi, S. D., \& ï. (2015). Use of Website and GIS Databases for Enhancement of Geosites in Algeria. https://doi.org/10.1007/978-3-319-10708-0_10

Aarseth, H. (2009). Situert refleksivitet: det narrative selv mellom tilhørighet og distanse. Retrieved from http://ojs.novus.no/index.php/SID/article/viewFile/1013/1004

DANIEL KALLÓS. (2009). Varför är det så förtvivlat svårt att bygga upp forskning och forskarutbildning i anslutning till lärarutbildning och pedagogisk yrkesverksamhet?, 1401-6788. Retrieved from http://journals.lub.lu.se/ojs/index.php/pfs/article/viewFile/7740/6795

Filiz Boyaci, H., \& Topçu, V. (2014). Development of eggplant hybrid cultivar "BATEM FILIZI" and determination of yield performance. Araştırma Makalesi/Research Article Derim, 31(2), 11-22. Retrieved from http://www.derim.com.tr/download/article-file/53034

Guðmundsson, Ó., \& Crocker, S. D. (2010). Observing DNSSEC validation in the wild. Retrieved from http://www.npl.co.uk/upload/pdf/satin2011-Gudmundsson_3.pdf

Hardianti, G., Am, M. S., \& Huda, A. (2010). The Effect of Shaping Technic toward the Ability of Wearing T-Shirt for Child with Intelectual Disability ( Pengaruh Teknik Shaping Terhadap Kemampuan Memakai Kemeja Anak Tunagrahita ), 4(1), 56-62.

Jódar, P., Ortiz, L., Martí, J., \& Alós, R. (2004). Los perfiles de la afiliación sindical. Una propuesta metodológica a partir de un estudio de CCOO en Cataluña. Retrieved from 
https://www.researchgate.net/profile/Pere_Jodar/publication/39287764_Los_perfiles_de_la_afilia cion_sindical_Una_propuesta_metodologica_a_partir_de_un_estudio_de_CCOO_en_Cataluna/link s/0fcfd5139a1c35cb94000000.pdf

Leal, F., Arnaldo, J., \& Montevechi, B. (2008). UMA PROPOSTA DE TÉCNICA DE MODELAGEM CONCEITUAL PARA A SIMULAÇÃO ATRAVÉS DE ELEMENTOS DO IDEF. Retrieved from http://www.din.uem.br/sbpo/sbpo2008/pdf/arq0292.pdf

Orhan, Y1lmaz, \& I. (1994). QUERCUS PETRAEA sunsp, mERİcA YAPRAKLARIN DAKİ TOTAL FENOLiK niLEşiK MiKTAR1 ÜZERINE MEVSIMSEL DE(;|̧̇iKLIKKLERİN ETKİsì. Y.y.o. Vet.fak.lkrg, 5(12), 29-34. Retrieved from http://dergipark.gov.tr/download/article-file/146985

Park, J., Chang, P.-H., Park, H.-S., \& Lee, E. (2006). Design of Learning Input Shaping Technique for Residual Vibration Suppression in an Industrial Robot. IEEE/ASME TRANSACTIONS ON MECHATRONICS, 11(1). https://doi.org/10.1109/TMECH.2005.863365

Rahim, A. H. M. A., \& Kandlawala, M. F. (2004). Robust STATCOM voltage controller design using loop-shaping technique. https://doi.org/10.1016/S0378-7796(03)00153-6

Skela-Savič, B., \& Lorber, M. (2014). Factors affecting nurses' organizational commitment Pripadnost medicinskih sester in opredelitev njenih dejavnikov, 48(484), 294-301.

https://doi.org/10.14528/snr.2014.48.4.34

Soto Carmona David Ruiz U A D, A. O. (1970). Afiliación, movilización y aliados políticos: las incógnitas del poder sindical español. Retrieved from

http://revistas.ucm.es/index.php/CRLA/article/viewFile/CRLA9393220107A/32665

Yoshida, M., Hayakawa, T., \& Hatsukade, M. (1979). Studies on Hemipterous insects injuring the turfgrass I Bionomics and damage to turfgrass by the Geoblissus hirtulus Burmeister. Retrieved from https://www.jstage.jst.go.jp/article/turfgrass1972/8/2/8_2_129/_pdf

吴开亚. (2008). 基于联系数的流域水安全评价模型. Retrieved from http://image.sciencenet.cn/olddata/kexue.com.cn/upload/blog/file/2010/9/201091814340835519 .pdf

徐, 海, 明, 何, 金, \&海. (2001). 江淮入梅的年际变化及其与北大西洋涛动和海温异常的联系. Retrieved from http://www.cmsjournal.net/qxxb_cn/ch/reader/create_pdf.aspx?file_no=20010606

Copyrights Holder: I Gede Krisna Yoga , I Ketut Gading, I Ketut Dharsana 2017

https://doi.org/10.23887/128202017

Open Access Article | CC-BY Creative Commons Attribution 4.0 International License. Word Count:
Conflict of Interest Disclosures:

The authors declare that they have no significant competing financial, professional or personal interests that might have influenced the performance or presentation of the work described in this manuscript.

First Publication Right: BISMA The Journal of Counseling

@creative 